\title{
INVESTIGATIONS ON THE CAUSES OF VACGINATION ENCEPHALITIS
}

\author{
BY \\ PROFESSOR A. ECKSTEIN. \\ (From the University Children's Clinic, Düsseldorf, Germany.)
}

The frequent occurrence of affections of the central nervous system following vaccinations has directed the attention of a wide circle of medical men in Germany to this disease. The two reports of the Vaccination Committee of the British Ministry of Health have contributed to clear up the character of the disease to a large extent. The investigations undertaken by the Dutch Ministry of Health showed very similar results and extended our knowledge of this peculiar disease. In Germany great

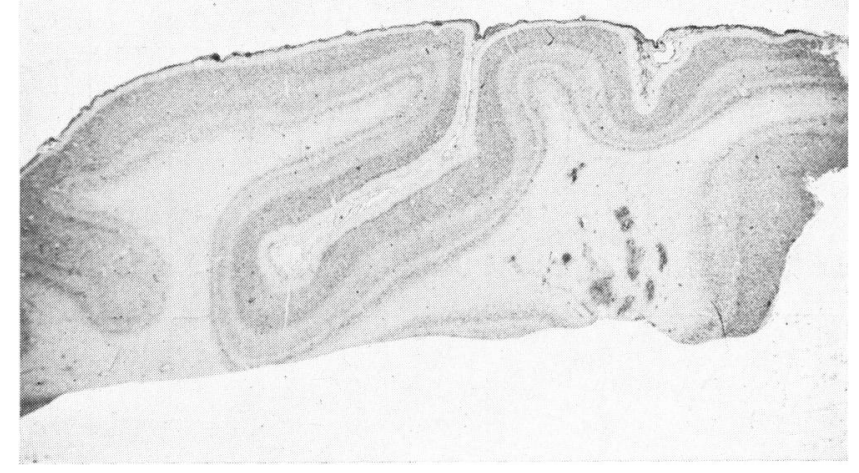
Fia. 1.-Perivascular infiltration of the medulla in
human vaccination encephalitis $(x)$.

difficulties were encountered in gathering facts regarding these cases, as the Committee appointed by the President of the Ministry of Health failed to reach a large number of the patients and subject them to suitable investigation. A survey of affections of the nervous system brought to the notice of the Ministry of Health as a result of prophylactic small-pox vaccinations undertaken from 1927 to 1930 , and passed on to the Committee of Inquiry (Eckstein, Gildemeister, Gins, Manteufel, Noeggerath, Pette) for further examination, comprised 102 cases, of which 77 (25 fatal) in first vaccinations and 4 (all fatal) in revaccinations were recognized to be definite affections of the nervous system following small-pox vaccination or coming under consideration under this head as probable or doubtful cases. When compiling the list a distinction was made between encephalitis and other affections of 
the nervous system following vaccination, such as meningitis and myelitis. In each of these two groups a distinction was also made between cases which were diagnosed by dissection, those clinically verified, and those which were probable, doubtful, to be declined, or unsuitable on account of lack of sufficient data. The compilation is as follows (Table 1):-

TABLE 1.

Crassification of Cases.

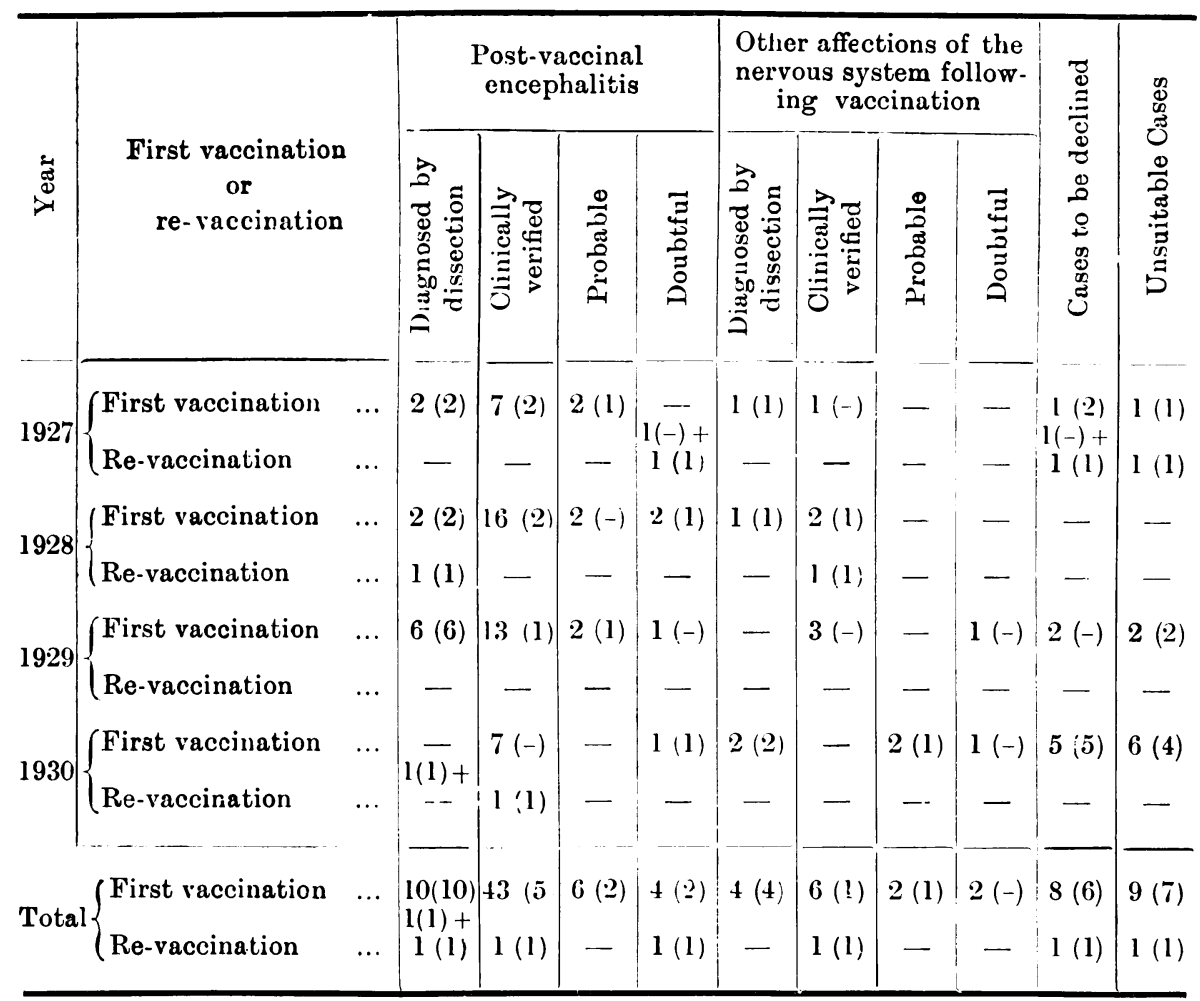

+ Affections on which the Committee could not form an unanimous opinion.

( ) Number of deaths.

In 193156 cases were notified to the Committee of which 33 ended fatally. But the data on these cases were so vague that even now the Committee is unable to state which cases are to be attributed to vaccination alone.

In contradistinction to other European countries vaccination in Germany is even to-day still regulated by law. The Vaccination Law enacted in 1874 has not since been altered to any great extent. A ' conscience clause' which would give the possibility of breaking through the vaccination law has so far never been sanctioned, although it has been asked for in many quarters. An amendment not yet determined by law has been recommended by the Ministry of Health which is to the effect that enforced vaccination does not appear to be advisable and that any injury directly arising from vaccination 
should be adequately indemnified. It was also suggested that in persons liable to receive vaccination who have suffered from acute infectious inflammatory diseases of the central nervous system, or still show sequelæ of such an affection, or whose relatives have suffered or are still suffering from such affections, vaccination should be postponed for at least one year. If requests are made to postpone vaccination more than twice, or in single cases for more than two years, the decision of the public vaccinating officer should be sought.

The vaccination technique which consists in making 4 incisions has not been altered, but in Germany 1 or 2 incisions are frequently made, as according to the regulations of the Vaccination Law vaccination is considered successful if one pustule arises. Moreover, only calf lymph which does not exceed a certain titre $(1$ in 10,000) is used for vaccination.

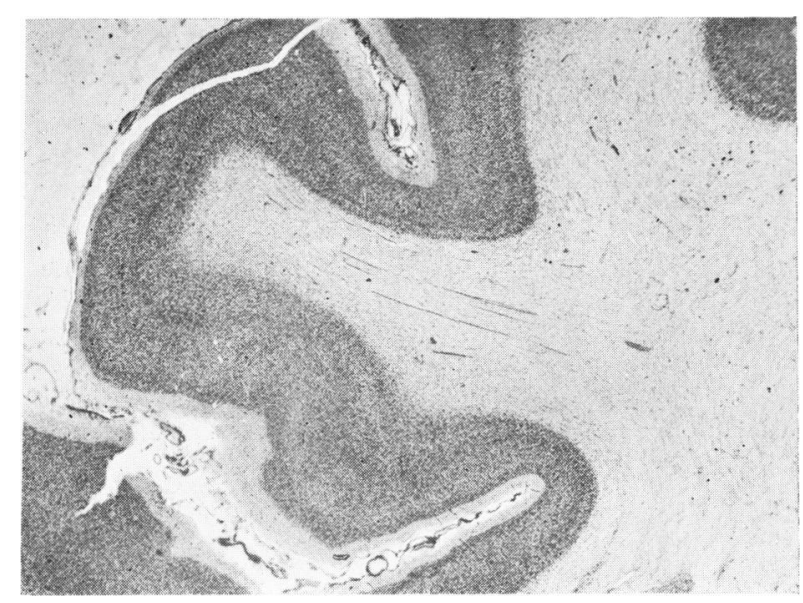

Fig. 2.-Perivascular infiltration of the medulla of a monkey with vaccination encephalitis $(\times 6)$.

On account of the support given us by the Ministry of the Interior, we, in conjunction with Hedwig Herzberg-Kremmer and Kurt Herzberg, were in a position to carry out clinical and animal experiments with a view to determining the course of vaccination and any injury to the central nervous system caused by the vaccine, which could provide fresh points of view for forming an opinion on vaccination encephalitis.

We succeeded in proving that even in normal persons the vaccine virus could be demonstrated in the blood with great regularity. These findings have since been confirmed by Gildemeister and Heuer. In these experiments we made use of the experiments of Othawara who after normal vaccination could demonstrate the vaccine virus in the blood by its retention in the testicle of a rabbit. The blood of most of the patients was positive between the third and tenth day, especially between the sixth and eighth day after vaccination, also when the clinical manifestations were present. 
Although the view expressed by Pirquet-that vaccination represents a local process accompanied by a secondary allergic reaction-was, considering certain abnormal vaccination reactions especially of general vaccines, not probable, and although the acquisition of a general immunity following vaccination was rather in favour of a general infection of the organism with vaccine virus, only our experiments on a larger material of normal vaccinated children definitely proved this point. The occurrence of these general infections, especially affections of the central nervous system following vaccination, has a certain importance as they find their analogues

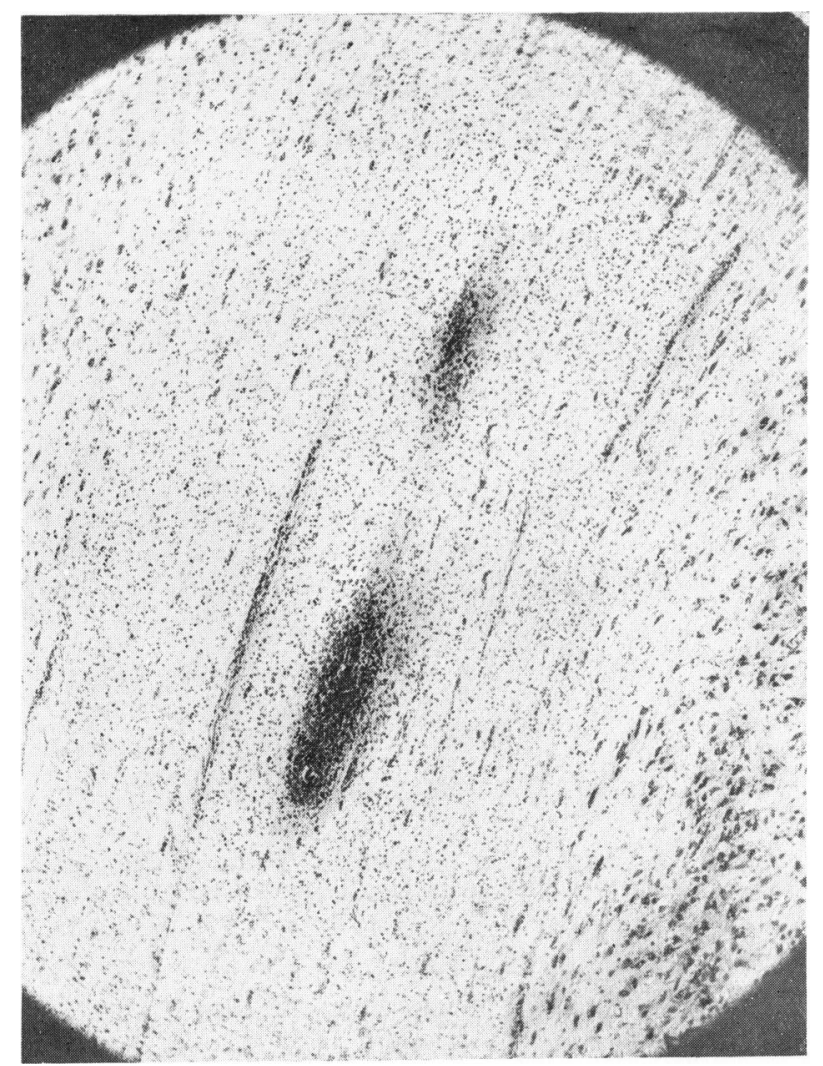

FIG. 3.-Perivascular infiltrations and hyperplasia of neuroglia in the medulla in human vaccination
encephalitis $(\times 60)$.

in numerous other infectious diseases. This view was also confirmed by our further observations that in no case of normal vaccination did we succeed in proving vaccine virus in the cerebrospinal fluid, whereas in 5 cases of vaccinal injury of the central nervous system it could be demonstrated. Similar observations were also made by Altershoff, Gildemeister and Huber. In one case, by intra-cerebral vaccination into a rabbit of cerebrospinal fluid from a child suffering from post-vaccinal encephalitis Herzberg was able to produce an encephalitis, 
There are two important points of view as to the causes of nervous complications following vaccination: (1) that the complications are due to an activation of the latent encephalitic germs caused by vaccination, or (2) that the vaccinations themselves are the cause of the complications. The ' activating theory' has hitherto not provided any definite clues to go upon.

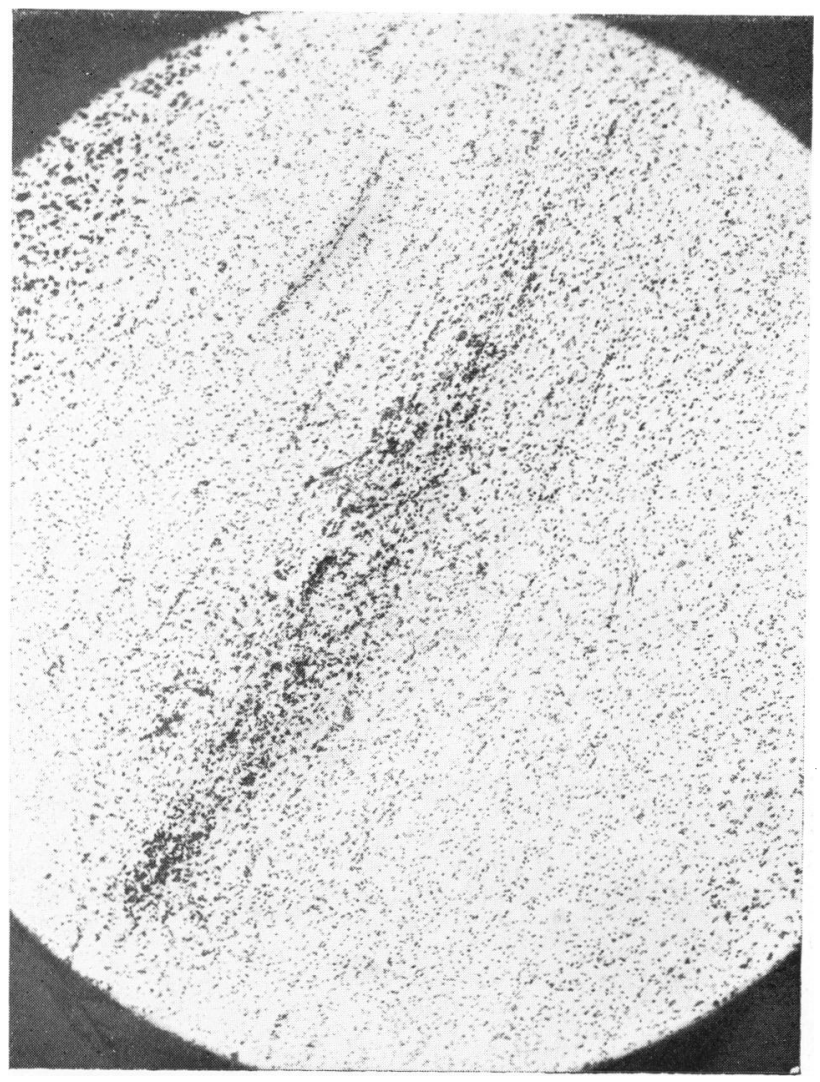

Fig. 4.-Perivascular infiltration and hyperplasia of neuroglia in the medulla of a monkey with vaccination encephalitis $(x 62)$.

Also the typical experiments carried out by Pette on rabbits, to which reference is frequently made, were not conclusive. In these animals suffering from a bifid flora (B. bipolaris) of the naso-pharynx produced by vaccination died of bifidus sepsis (bipolaris) without showing any encephalitic symptoms. Similar experiments carried out by Bürger and his associates resulted in a negative finding. By excluding these possibilities the view gains ground that the vaccine virus itself is to be regarded as the actual cause of the complications. Our clinical observations mentioned above are in favour of this theory. In further experiments on monkeys we were able to demonstrate that the presence of vaccine virus in the blood (also 


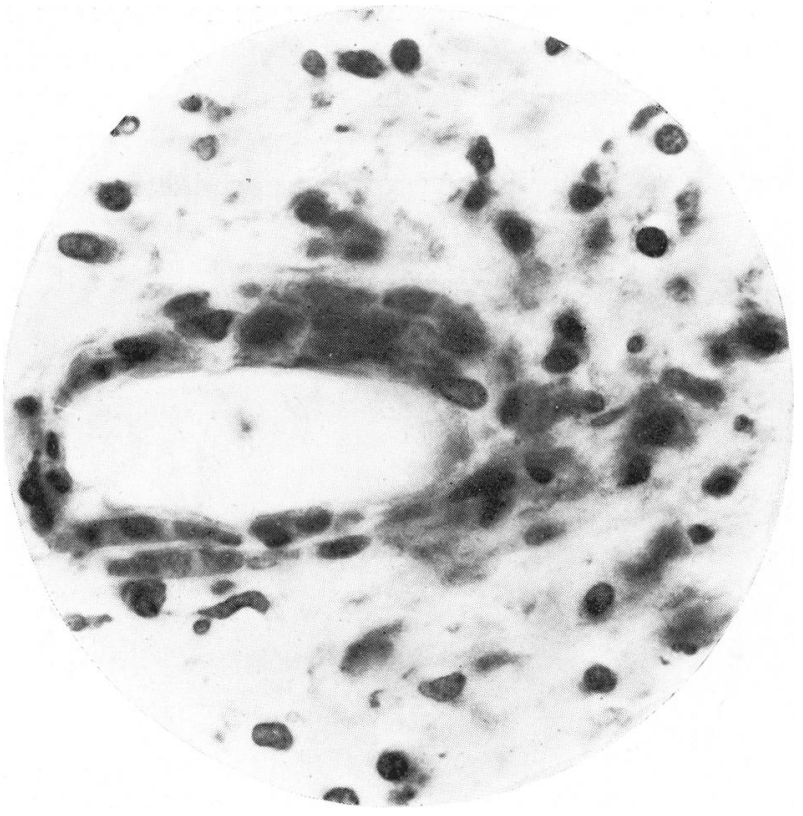

Fig. 5.-Blood vessel with infiltration macrophages and hyperplasia of neuroglia: human $(\times 720)$.

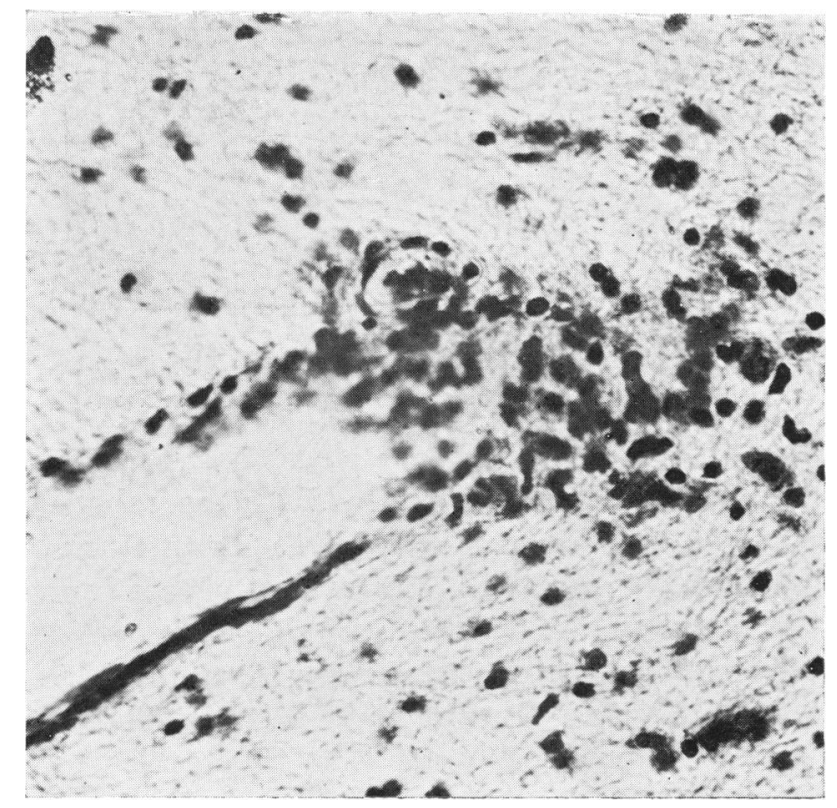

FIG. 6.-Infiltration macrophages and hyperplasia of neuroglia in monkey vaccination encephalitis $(x 476)$. 
by directly injecting large quantities of the vaccine virus into the bloodstream) did not give rise to any nervous affections as long as the barrier between blood and cerebrospinal fluid, as well as between blood and brain, is still intact. On the other hand, the presence of vaccine virus in the cerebrospinal fluid, also in very great dilutions, is connected with a meningo-myeloencephalitis running a typical course. In other experiments by producing different degrees of disturbance of the circulation of the central nervous

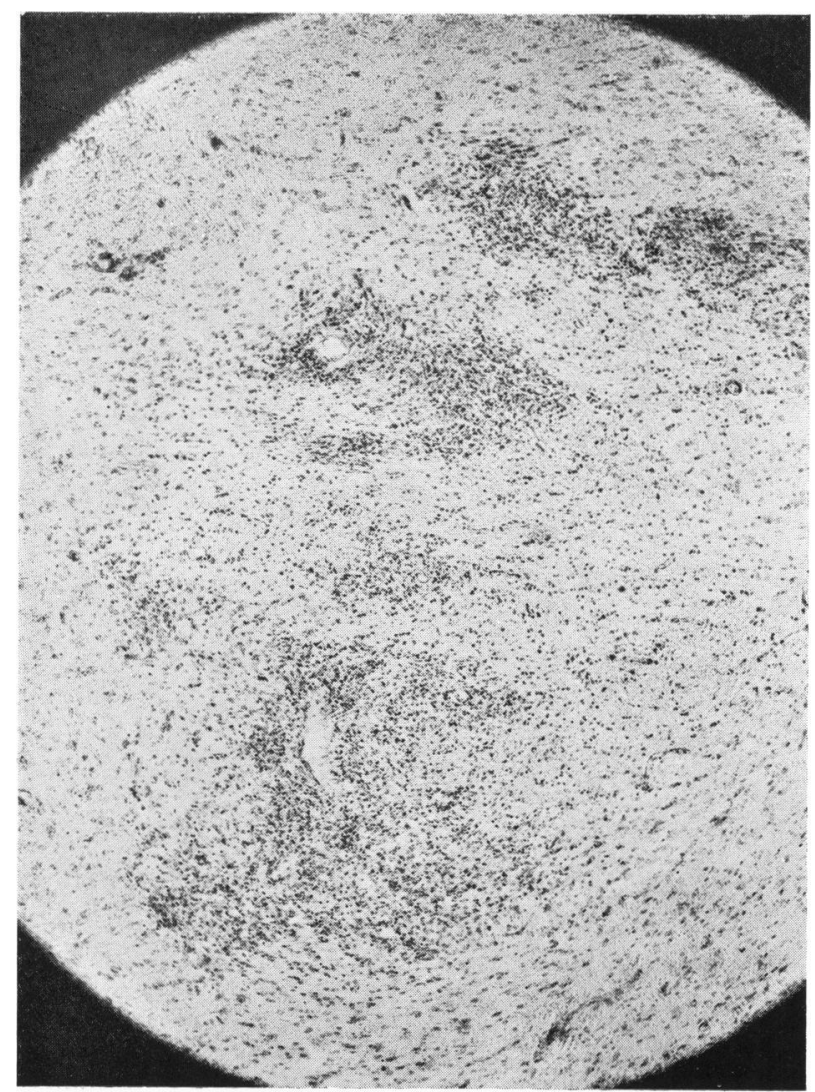

Fig. 7.-Perivascular infiltrations and patches of glia in the medullary substance of the cerebrum : human $(x 61)$.

system (unilateral ligature of the jugular vein, transitory diathermy of the brain), and by simultaneously introducing the vaccine virus into the blood, we also succeeded in producing symptoms in monkeys which had a great clinical and morbid anatomical similarity to the so-called vaccination encephalitis observed in human beings. We obtained the same result by disturbing the current of cerebrospinal fluid by continuous lumbar punctures. A certain relationship may be found to the investigations undertaken by 
Jowelews who used Speransky's 'pompage' method and was able to produce the hydrophobia virus in the brain of rabbits. In one experimental animal which had been treated with diathermy, there existed in addition to the vaccination encephalitis a generalized vaccinia of the skin in the region of the diathermy (corresponding to an observation made by Weichsel in a case of vaccination encephalitis).

As the experiments were carried out with a standardized (human) vaccine which was always previously tested as to its sterility, here only the vaccine virus comes into consideration as the injuring agent.

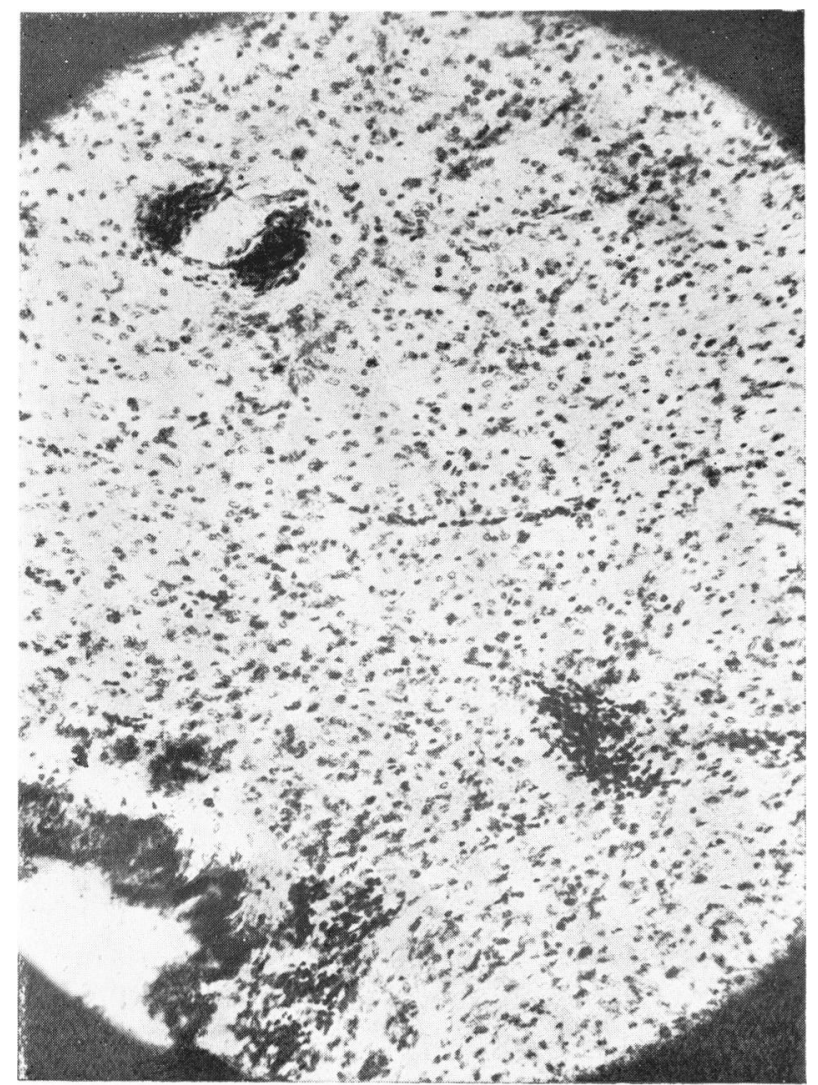

Fig. 8.-Perivascular infiltrations and hyperplasia of neuroglia in the neighbourhood of the ventricle in monkey vaccination encephalitis $(\times 150)$.

When trying to form an opinion as to the cause of vaccination encephalitis in human beings, attention was drawn over and over again to the fact that only in isolated cases has it been possible to prove vaccine virus in the brain of patients who died of vaccination encephalitis. But this proof loses its conclusive force in so far as the presence of vaccine virus in the blood is normal during the period in question and therefore should, of course, not be looked upon as being pathogenic in the brain. 


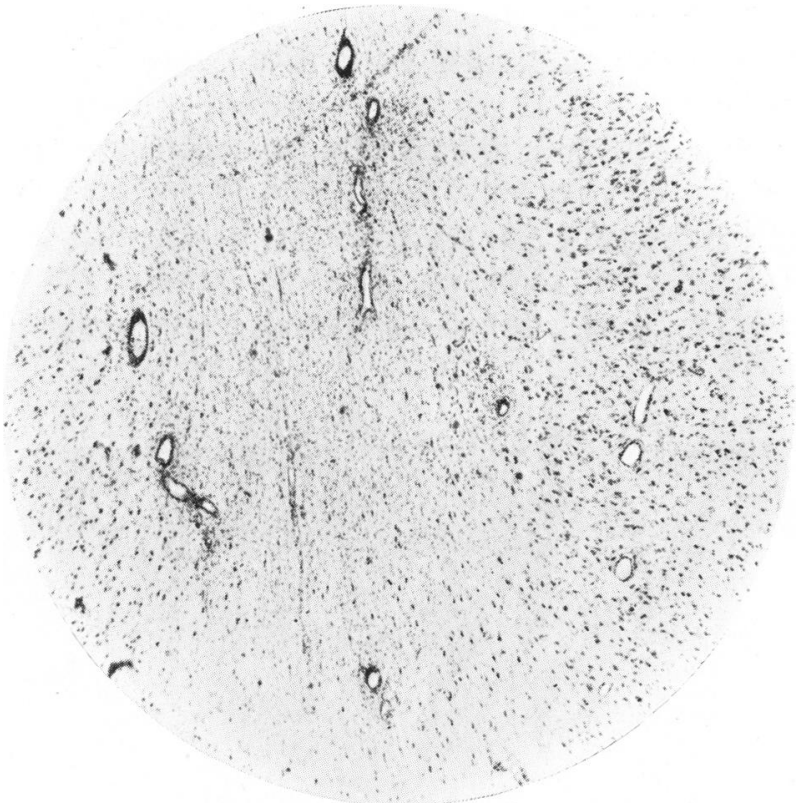

FIG. 9.-Disseminated foci in the medulla of the insula (island of Reil): human ( $\times 35)$.

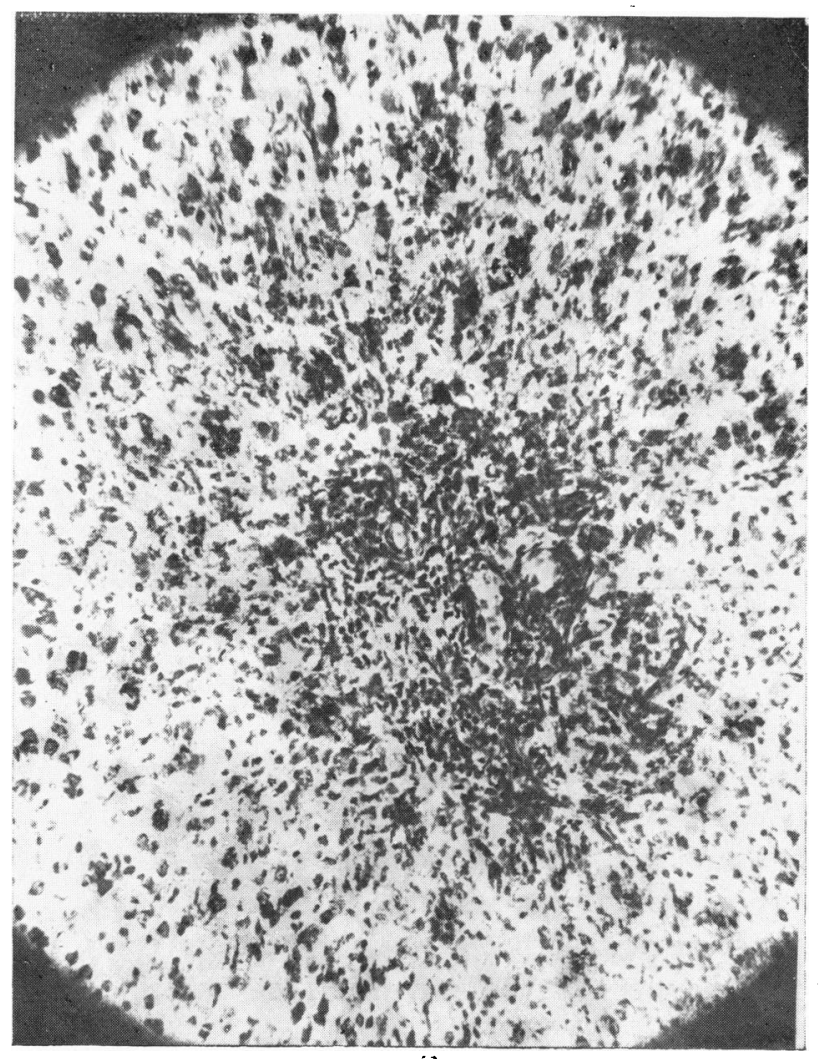

FIG. 10.-Perivascular infiltration in monkey vaccination encephalitis ( $x$ 147). 
This question was also cleared up by experiments carried out by Herzberg. He was able to furnish proof that in the majority of cases a condition of self-sterilization exists at the moment of death which prevents vaccine virus from being demonstrable. In experiments on animals (rabbits), by giving direct cerebral injections and gradually increasing the massiveness of the infection, he succeeded in proving that from a certain limit onwards the animals show a protracted course of the disease which nevertheless ends fatally with symptoms of meningo-encephalitis. In animals

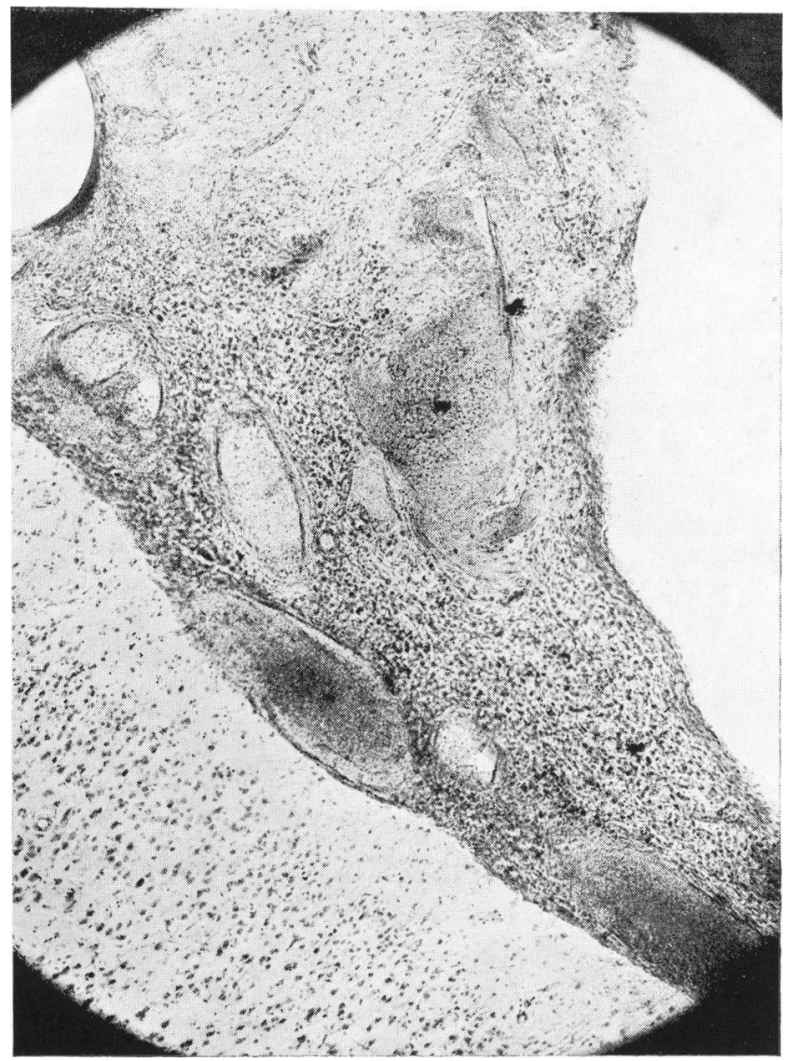

FIG. 11.-Marked meningeal reaction in vaccination encephalo-meningitis: human $(\times 61)$.

which died at a later period with characteristic symptoms vaccine virus could no longer be demonstrated, in contradistinction to those animals which died after a few days with very marked symptoms. The animals therefore died of the consequences of the nervous complications after the virus itself had meantime been destroyed. These vaccination tests explain satisfactorily the failure to find the virus in the brain of patients suffering from vaccination encephalitis. 
The only question still to be cleared up is why certain individuals are affected by nervous vaccination complications, whereas in thousands of children who have been vaccinated with the same lymph vaccination runs a normal course. Cases should not be included for consideration when many other children living in the same district fall ill at the same time, e.g., the outbreak in 1930 in Stubaital (Tirol). In this large epidemic of cases showing nervous complications of vaccination, Reich was able to prove that children not vaccinated but living in the same district were also attacked by encephalitic symptoms. Here a local encephalitis epidemic is obviously present, the occurrence of which is not to be ascribed to vaccination.

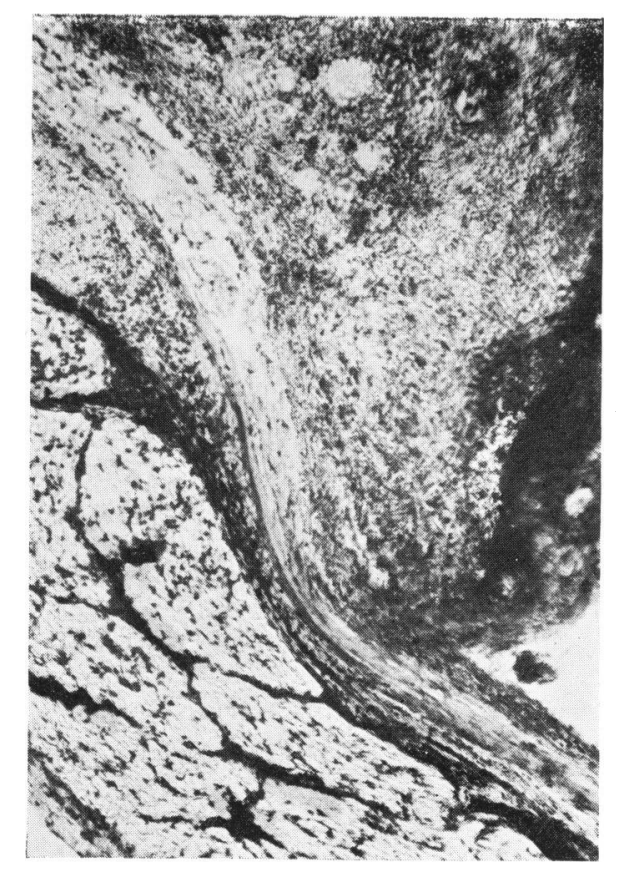

Fig. 12.-Meningeal reaction in monkey vaccination encephalitis $(\times 129)$.

However, most of the instances of nervous vaccinal complications recorded are isolated cases. In normal vaccinated persons permeability is not increased, as I was able to convince myself with the aid of Walther's bromine method: therefore an individual disposition to such disturbances must exist. This individual disposition, the constitutional factor of which displays itself in the occasional occurrence of nervous vaccination complications among brothers and sisters, is after all assumed for all nervous affections of the central nervous system. The affection of the central nervous system following vaccination would, therefore, also confirm our observations in this direction. 


\section{REFERENCES.}

Eckstein, A., et al. Reichs-Gesundhbl., Berlin, 1931 XXXVII, 573.

Eckstein, A., Klin. Wchnsch., Berlin, 1929, VIII, 1153; 1931, X, 408: Ztschr. $f$. Kinderh., Berlin, 1930, XLIX, 218: Ztschr. f. Hyg., Berlin, 1930, CXI, 659 \& 669; 1931, CXII, 151; 1932, CXIII, 371.

Eckstein, A., Herzberg-Kremmer, H., \& Herzberg, K., Deutsche Med. Wchnsch., Leipsic, 1930, LVI, 264 \& 1429.

Herzberg, K., Klin. Wchsch., Berlin, 1931, X, 1626 : I. congres internat. d. Microbiol., Paris, 1930 : Zentralbl. f. Bakt., Jena, 1931, CXXII, 231.

Herzberg-Kremmer, H., \& Herzberg, K., Zentralbl. f. Bakt., Jena, 1930, CXV, 271; 1930, CXIX, 175; 1931, CXXII, 223. 